\title{
NACIONALIDAD Y CIUDADANÍA COMO ELEMENTOS FORMALES DE LAS CANDIDATURAS A PUESTOS DE ELECCIÓN POPULAR EN EL ORDENAMIENTO JURÍDICO MEXICANO
}

\author{
NATIONALITY AND CITIZENSHIP AS FORMAL ELEMENTS OF \\ CANDIDACY TO POSITIONS OF POPULAR ELECTION IN THE MEXICAN \\ LEGAL ORDER
}

Recibido/Received: 12/05/2017

Modificado/Modified: 30/06/2017

Aceptado/Accepted: 27/09/2017

\section{RESUMEN}

El presente trabajo tiene como finalidad mostrar cómo la nacionalidad y la ciudadanía son elementos formales que exige la Constitución mexicana para ocupar cualquier puesto de elección popular a nivel federal dentro del ordenamiento jurídico mexicano. En este sentido, cabe aclarar que el sistema jurídico mexicano no brinda un concepto de lo que debe entenderse por nacionalidad y ciudadanía. Sin embargo, la Constitución sí establece los requisitos de cómo adquirir la nacionalidad y cómo perder la nacionalidad. Asimismo, para que una persona tenga la calidad de ciudadano debe cumplir con los siguientes requisitos: tener un modo honesto de vivir y haber cumplido 18 años de edad. Por lo tanto, no todos los mexicanos son ciudadanos, condición indispensable para postularse como candidato a cualquier cargo de elección popular.

\section{PALABRAS CLAVE}

Nacionalidad; ciudadanía; candidatura; elecciones; México.

\section{SUMARIO}

1. Introducción. 2. Cuestiones previas. 3. Concepto de nacionalidad y ciudadanía: su fundamento constitucional. 4. La ciudadanía como elemento formal para ser presidente de los Estados Unidos Mexicanos. 5. La ciudadanía como elemento formal para ser diputado y senador. 6. Conclusiones. Bibliografía.

\section{ABSTRACT}

This paper has as purpose to show how the nationality and citizenship are formal elements that demand the Mexican Constitution to take over any position of popular election to federal level in the Mexican legal order. In this sense, it is worth mentioning that the Mexican legal order does not give a concept about how to understand nationality and citizenship. However, the Constitution establishes the requirements on how to acquire the nationality and how to lose it. Likewise, so that a person has the quality of a citizen has to fulfill the following requirements: to have an honest way of living, and to be 
18 years old. Thus, not every Mexican is a citizen, indispensable condition to be candidate to any position of popular election.

\section{KEYWORDS}

Nationality; citizenship; candidacy; elections; Mexico.

\section{CONTENTS}

1. Introduction. 2. Previous issues. 3. Concept of nationality and citizenship: its constitutional basis. 4. Citizenship as a formal element to be president of the Mexican United States. 5. Citizenship as a formal element to be deputy and senator. 6. Conclusions. References.

\section{INTRODUCCIÓN}

El presente trabajo se encuentra dividido en cuatro partes. En la primera, mostramos cuál ha sido el panorama del sistema electoral mexicano. En cambio en la segunda parte nos centramos en la cuestión principal de nuestro objeto de estudio: la ciudadanía y la nacionalidad, definimos ambos conceptos, debido a que en el ordenamiento jurídico mexicano no se brinda una definición de los conceptos comentados. Asimismo, la Constitución mexicana en sus artículos 30 y 37 señala cómo se adquiere y cómo se pierde la nacionalidad. Por otro lado, el artículo 34 establece los requisitos para ser ciudadano mexicano, siendo indispensable tener 18 años de edad.

Por otro lado, en los puntos tres y cuatro analizamos cómo dentro de los requisitos para ser, ya sea, presidente de la república, diputado o senador, la Constitución exige como primer requisito, tener la ciudadanía mexicana. De lo contrario no se puede aspirar a ningún cargo de elección popular dentro del ordenamiento jurídico mexicano. Uno de los documentos que adquiere gran relevancia es la credencial para votar con fotografía, la cual es emitida por el Instituto Nacional Electoral. Con el documento mencionado, aparte de hacerse valer los derechos políticos-electorales como votar, se puede acreditar también la nacionalidad según lo ha establecido la Suprema Corte de Justicia de la Nación, tal y como veremos.

\section{CUESTIONES PREVIAS}

En 1917 con la promulgación de la Constitución Política de los Estados Unidos Mexicanos, el 5 de febrero de ese año, se instituye a la Junta Empadronadora, las Juntas Computadoras Locales y los Colegios Electorales como organismos encargados de organizar y calificar los procesos para elegir al Presidente de la República y los miembros del Congreso de la Unión. Aunque, fue hasta 1946 cuando el Presidente Manuel Ávila Camacho promulga la Ley Federal Electoral y crea la Comisión Federal de Vigilancia Electoral, conformada por el Secretario de Gobernación y otro miembro del gabinete, un diputado, un senador y dos representantes de los partidos políticos con mayor relevancia. De igual forma, la Ley ordena la creación de comisiones electorales locales y el Consejo del Padrón Electoral.

La Ley federal electoral de 1946 es el inicio de la reglamentación de los procesos electorales en México, surgiendo asimismo, la Comisión Federal de Vigilancia Electoral, las comisiones locales electorales, los comités distritales electorales y el Consejo de padrón Electoral, siendo el Gobierno Federal responsable del proceso electoral. También, se reforma 
el capítulo dedicado a los partidos políticos, definiéndolos y estableciéndose los requisitos para su creación (García, 2011: 79).

Anterior a la Ley federal electoral de 1946, no se preveía expresamente un sistema para convocar elecciones, razón por la cual, surge la Ley electoral Federal de 4 de diciembre de 1951, con el fin de regular tal situación. Además, otro de los aspectos importantes de esta Ley es la contemplación de medios de defensa en caso de existir irregularidades en el proceso electoral, pon otra cosa se podía interponer un escrito ante el organismo jerárquico superior acompañándose de las pruebas correspondientes. Éste recurso se resolvía a los tres días de su interposición, a menos que hubiere diligencias que practicar. En el precepto número 45 de la normativa comentada queda definido el concepto de Registro Nacional de Electores (Martínez, 2010:156).

Siguiendo con la consolidación de la materia electoral en México aparece la Ley Federal Electoral de 5 de enero de 1973. Dentro de sus puntos importantes se pueden mencionar los siguientes:

1. Se estableció la credencial de elector permanente;

2. Se creó el Registro Nacional de Electores;

3. Se otorgan nuevos derechos a los partidos políticos, tales como, la exención de impuestos y acceso a la radio y televisión durante el periodo electoral; y

4. Se da cumplimiento al principio de democracia y pluralidad política, al establecerse como derecho de los partidos políticos a tener un representante en lo conformación de los órganos electorales (ibídem: 157).

Cabe mencionar que hasta antes de 1977, no se había dado una reforma estructural en materia de justicia electoral, por lo tanto prevalecía un sistema de autocalificación en las elecciones, en donde solo los integrantes del Poder Legislativo federal participaban, teniendo una escasa actuación la Suprema Corte de Justicia de la Nación. Para contrarrestar tal situación, en 1977 se reforma la Constitución en varios artículos en relación con la justicia en materia electoral, siendo las más destacadas las previstas en los artículos 60 y 97. Con la modificación del artículo 60 se encargó a un colegio electoral la calificación de las elecciones, creándose un Recurso de Reclamación (art. 97) ante la corte, pero sin convertir el sistema en un contencioso-jurisdiccional (Martínez: 158).

Durante este periodo surge Ley Federal de Organizaciones Políticas y Procesos Electorales (LFOPPE). La cual reguló los ingresos de los partidos políticos en la escena electoral. Se dispensa a los partidos políticos del presupuesto de acreditar 65.000 miembros en la mitad de los Estados de la federación o de los distritos electorales, lo cual era un requisito indispensable para obtener el registro definitivo (art. 27). Se deja en manos de la Secretaría de Gobernación el registro de coaliciones y de candidaturas comunes (arts. 48, 60 y 67). Aunado a lo anterior, se previó la representación proporcional con el fin de apoyar a los partidos con pocos miembros y reducir la sobrerrepresentación del PRI (García, 2011: 79).

La reforma política publicada el 15 de diciembre de 1986, trajo como consecuencia directa la creación del Tribunal de lo Contencioso Electoral (TRICOEL). El cual en su momento fue un órgano autónomo de carácter administrativo, integrado por siete magistrados numerarios y dos supernumerarios, los cuales eran nombrados por el Congreso de la Unión; teniendo un carácter mixto, es decir, resolvía impugnaciones administrativas (p. ej., la revocación y la revisión) y jurisdiccionales (p. ej., el recurso de apelación y la queja). $\mathrm{Su}$ actuación principal se dio con motivo de la celebración de las elecciones federales de 1988, en donde tuvo la responsabilidad de sustanciar y resolver los recursos de quejas derivados de las impugnaciones en la elección de diputados, senadores y la elección presidencial (Martínez, 2010: 127). Anterior a la elección de 1988, la reforma electoral de 
1987 dio lugar al Código Federal Electoral el cual tal y como aclara García tuvo como propósito los siguientes objetivos:

[...] 1) ampliar los espacios de representación, aumentando a 200 las curules de representación proporcional, pero permitiendo que el PRI participara de dicho reparto; 2) evitar la pulverización del espectro político, limitando el acceso de los partidos políticos a la arena electoral con la eliminación del registro condicionado y de la figura de las asociaciones políticas; 3) reforzar el control oficial sobre los organismos electorales para que el gobierno ya no tuviera que depender de la alianza con los llamados partidos paraestatales; 4) fortalecer la posición mayoritaria en la Cámara de Diputados (a través del llamado candado de gobernabilidad); y 5) dar cauce a las impugnaciones que surgieran por irregularidades en los procesos (García, 2011: 79).

Como podemos observar, la regulación de la materia electoral en México, a través de los años ha tenido un camino largo, es decir, una obra en construcción permanente, ya que como veremos a lo largo de las presentes líneas, las reformas de los años noventa tuvieron una repercusión de gran calado, al crearse el Instituto Federal Electoral (IFE), el cual en las últimas tres décadas ha dado validez y legitimidad a las elecciones federales, tanto de diputados, senadores, y la elecciones presidenciales de los años 1994, 2000, 2006 y 2012. El origen del IFE como institución independiente del gobierno se da después de lo ocurrido en las elecciones federales de 1988, en donde surge electo presidente Carlos Salinas de Gortari para el sexenio 1988-1994. Las elecciones comentadas fueron criticadas ampliamente por los especialistas en ciencia política, así como por los historiadores, debido a que en aquel momento, el gobierno ejercía una influencia directa en los procesos electorales, siendo la Secretaría de Gobernación la encargada de verificar y calificar el recuento de votos a través de la Comisión Federal Electoral.

Sin embargo, mediante La reforma constitucional en materia política-electoral, publicada el 10 de febrero de 2014 rediseñó el régimen electoral mexicano y transformó el Instituto Federal Electoral (IFE) en una autoridad de carácter nacional: el Instituto Nacional Electoral (INE), a fin de homologar los estándares con los que se organizan los procesos electorales federales y locales para garantizar altos niveles de calidad en nuestra democracia electoral. Además de organizar los procesos electorales federales, el INE se coordina con los organismos electorales locales para la organización de los comicios en las entidades federativas.

Por otro lado, el Consejo General del INE se compone de 11 ciudadanos elegidos por la Cámara de Diputados. Uno de ellos funge como Consejero Presidente y los 10 restantes como Consejeros Electorales.

Asimismo, el INE cuenta con un Servicio Profesional Electoral Nacional (SPEN) para asegurar la imparcialidad y profesionalismo de todos los funcionarios que participan en la organización de elecciones, tanto a nivel federal como local. El Consejo General del INE designa a los consejeros de los organismos electorales locales y puede asumir funciones que le corresponden a dichos institutos en los casos que la Ley prevea.

De acuerdo con la reforma constitucional, entre las funciones principales del INE se encuentran las siguientes:

1. Organizar la elección de los dirigentes de los partidos políticos a petición de estas organizaciones.

2. Garantizar que los candidatos independientes tengan acceso a tiempos del Estado en radio y televisión, para que puedan difundir sus campañas. 
3. Verificar que se cumpla el requisito mínimo (2\% de la lista nominal) para solicitar el ejercicio de las consultas populares y realizará las actividades necesarias para su organización, incluido el cómputo y la declaración de resultados.

4. Fiscalizar los recursos de los partidos políticos nivel federal y local en forma expedita, es decir, en el transcurso de las campañas y no una vez que terminen.

Una vez descrito como se encuentra el estado de la cuestión en el ordenamiento jurídico mexicano, por lo que respecta a la materia electoral, aclararemos que el presente trabajo, tiene como objetivo mostrar cómo la nacionalidad y la ciudadanía son elementos formales de las candidaturas a los cargos de elección popular en el ordenamiento jurídico mexicano.

Asimismo, las figuras jurídicas mencionadas en el párrafo anterior, encuentran su fundamento jurídico en la Constitución Política de los Estados Unidos Mexicanos (en adelante CPEUM), artículos 34 y 37 . No obstante la norma mencionada no brinda una definición de lo que debe entenderse por nacionalidad y ciudadanía, a pesar de hacer referencia en varios de sus preceptos. En este sentido recurriremos a la doctrina autorizada para definir ambos conceptos.

Por otra parte, a nivel federal los únicos puestos a elección popular que la CPEUM permite son los de presidente de la república, senador y diputado. Siendo requisito esencial tener nacionalidad mexicana y por ende la ciudadanía. Tal y como veremos en las siguientes líneas.

\section{CONCEPTO DE NACIONALIDAD Y CIUDADANÍA: SU FUNDAMENTO CONSTITUCIONAL}

Para entender los conceptos de nacionalidad y ciudadanía, se parte de la concepción de Estado que representa la organización política de la nación, que se debe entender como la colectividad organizada jurídicamente en un territorio; los elementos de éste son territorio, población y poder. El territorio radica en considerar al mismo como una circunscripción en cuyo interior ejerce el poder el Estado, la población es la pertenencia de los individuos a una comunidad, ya sea transitoria o permanente. (Van der Laat, 1998). En la doctrina tenemos que el término nacionalidad ha tenido dos nociones la sociológica, y la noción jurídica, desde este enfoque, es reconocido jurídicamente a un determinado individuo frente al Estado como organización política. Además, de tener presente que la nacionalidad es un derecho fundamental de la persona (Lapiedra et al, 2011:17)

Si bien la Constitución no da un concepto de nacionalidad. Si hace referencia implícita a ella en su artículo 30 al declarar:

Artículo 30. La nacionalidad mexicana se adquiere por nacimiento o por naturalización.

A) Son mexicanos por nacimiento:

I. Los que nazcan en territorio de la República, sea cual fuere la nacionalidad de sus padres.

II. Los que nazcan en el extranjero, hijos de padres mexicanos nacidos en territorio nacional, de padre mexicano nacido en territorio nacional, o de madre mexicana nacida en territorio nacional;

III. Los que nazcan en el extranjero, hijos de padres mexicanos por naturalización, de padre mexicano por naturalización, o de madre mexicana por naturalización, y

IV. Los que nazcan a bordo de embarcaciones o aeronaves mexicanas, sean de guerra o mercantes.

B) Son mexicanos por naturalización: 
I. Los extranjeros que obtengan de la Secretaría de Relaciones carta de naturalización.

II. La mujer o el varón extranjeros que contraigan matrimonio con varón o con mujer mexicanos, que tengan o establezcan su domicilio dentro del territorio nacional y cumplan con los demás requisitos que al efecto señale la ley.

Sin embargo, el artículo 37 señala los casos en que la nacionalidad se perderá cuando aclara:

A) Ningún mexicano por nacimiento podrá ser privado de su nacionalidad.

B) La nacionalidad mexicana por naturalización se perderá en los siguientes casos:

I. Por adquisición voluntaria de una nacionalidad extranjera, por hacerse pasar en cualquier instrumento público como extranjero, por usar un pasaporte extranjero, o por aceptar o usar títulos nobiliarios que impliquen sumisión a un Estado extranjero, y

II. Por residir durante cinco años continuos en el extranjero.

C) La ciudadanía mexicana se pierde:

I. Por aceptar o usar títulos nobiliarios de gobiernos extranjeros;

II. Por prestar voluntariamente servicios o funciones oficiales a un gobierno extranjero, sin permiso del Ejecutivo Federal;

III. Por aceptar o usar condecoraciones extranjeras sin permiso del Ejecutivo Federal.

El Presidente de la República, los senadores y diputados al Congreso de la Unión y los ministros de la Suprema Corte de Justicia de la Nación podrán libremente aceptar y usar condecoraciones extranjeras;

IV. Por admitir del gobierno de otro país títulos o funciones sin previo permiso del Ejecutivo Federal, exceptuando los títulos literarios, científicos o humanitarios que pueden aceptarse libremente;

V. Por ayudar, en contra de la Nación, a un extranjero, o a un gobierno extranjero, en cualquier reclamación diplomática o ante un tribunal internacional, y

VI. En los demás casos que fijan las leyes.

Como se observa, los preceptos comentados solo señalan los casos en que se adquiere y pierde la nacionalidad. Sin embargo, no especifican que debe entenderse por nacionalidad. Sin embargo, al analizar la (Ley de Nacionalidad, 20102), así como la (Ley General de Población, 2015: artículo 99), que son reglamentarias de los preceptos constitucionales, reiteran los requisitos de nacional conforme a la misma Carta Magna, pero refieren en su articulado el documento que consiste en acta de nacimiento, como referente para que las autoridades verifiquen la nacionalidad de la persona. En este sentido, la doctrina ha señalado que el concepto de nacionalidad implica pertenencia, una vinculación o enlace de un individuo hacia un grupo en particular, sin necesidad de comprender dentro de esos vínculos, aspectos de carácter jurídico o político, sino únicamente considerar la conciencia empírica de cada ser humano, las cuestiones primarias que tiene cada hombre procedentes de la comunicación social con otros hombres (Carpizo, 2011: 181). De lo anterior se desprende que el concepto de nacionalidad tiene una connotación sociológica y política, razón por la cual, se encuentra íntimamente ligado al concepto de nación.

La suprema Corte de Justicia de la Nación, Gaceta de Jurisprudencia y Tesis en materia electoral, Tribunal Electoral del Poder Judicial de la Federación, Año 4, Número 8, 2011, páginas 16, 17 y 18, en relación con la nacionalidad ha señalado lo siguiente:

"De conformidad con lo previsto en los artículos 30, inciso B), fracciones I y II; 34, 35, fracción I, y 36, fracción III de la Constitución Política de los Estados Unidos Mexicanos; 6, párrafos 1 y 2; 180, párrafos 2 y 4, del Código Federal de Instituciones y Procedimientos 
Electorales, así como Tercero Transitorio de la Ley de Nacionalidad, las declaratorias de nacionalidad mexicana por naturalización expedidas por la Secretaría de Relaciones Exteriores con antelación a la entrada en vigor de la Ley de Nacionalidad vigente, son documentos con los que se acredita la nacionalidad mexicana y, en consecuencia, idóneos para realizar los trámites necesarios para la obtención de la credencial para votar con fotografía, toda vez que el hecho de que no se encuentre enunciado en el catálogo aprobado para dichos efectos por la Comisión Nacional de Vigilancia del Registro Federal de Electores del Instituto Federal Electoral, es insuficiente para hacer nugatorios los derechos político-electorales adquiridos por naturalización, máxime cuando los documentos de identificación aprobados por esa comisión son preferentes y no limitativos" (Nación, 2011).

De la tesis comentada podemos observar que con ciertos documentos, en este caso la credencial de elector para votar con fotografía se acredita la nacionalidad mexicana. No obstante, para tramitar la credencial de elector se exigen cualquiera de los siguientes documentos, tal y como lo aclara el Instituto Nacional Electoral (INE):

\section{Un medio de identidad. Documento que acredite tu nacionalidad mexicana}

a) Acta de Nacimiento en original o documento análogo expedido de conformidad con la normatividad de las diferentes entidades federativas en materia del Registro Civil; o por los consulados o embajadas de México.

b) Documento que acredite la nacionalidad mexicana por naturalización.

Si presentas un documento que acredite tu nacionalidad mexicana por naturalización, y ésta no cuente con algún apellido del ciudadano, fecha y/o lugar de nacimiento, podrás presentar el acta de nacimiento de tu país de origen debidamente legalizada o apostillada y, en su caso, traducida por autoridad mexicana o instituciones autorizadas en la que se contenga dichos datos, o documento expedido por autoridad mexicana en dónde se señale la fecha y lugar de nacimiento.

\section{Una identificación con fotografía}

Deberán ser originales y vigentes, o con una fecha de expedición no mayor a 10 años cuando no tengan vigencia.

Además de identificarte con un medio de nacionalidad mexicana, deberás identificarte con alguna de sus huellas dactilares.

Cuando el trámite solicitado sea de inscripción o de reincorporación al Padrón Electoral, no se cuente con las huellas dactilares, o que alguno de los documentos de identificación señalados en el apartado anterior no contenga fotografía, deberás presentar alguno de los documentos de identificación con fotografía siguientes:

a) Cartilla del Servicio Militar Nacional; b) Pasaporte; c) Cédula Profesional;

d) Licencia o permiso para conducir; e) Credenciales de identificación laboral;

e) Credenciales de Identificación como usuarios o derechohabientes de servicios;

f) Documentos expedidos por escuelas con reconocimiento oficial e INEA;

g) Credencial para Votar. Será válida cuando se trate de reemplazo por pérdida de vigencia o un trámite derivado de éste, a excepción de la corrección de datos personales.

h) Otros documentos.

Credenciales de identificación laboral.

a) Instituciones del Sector Salud federal, estatal y municipal.

b) Servidores Públicos de los sectores central y paraestatal, así como de organismos autónomos constitucionales, Poder Legislativo y Poder Judicial a nivel federal o local. 
c) Iniciativa Privada siempre que cuenten con denominación o razón social y Registro Federal de Contribuyentes de la empresa, nombre y firma del patrón o su representante y nombre del ciudadano tal como aparece en el Acta de Nacimiento.

d) Escuelas públicas o privadas con reconocimiento oficial de nivel básico, medio, técnico, medio superior, superior e Instituto Nacional para la Educación de los Adultos (INEA)

Credenciales de identificación como usuarios o derechohabientes.

a) Instituciones del sector salud federal, estatal y municipal (no se incluye el carnet de citas médicas, ni otro tipo de constancias o pólizas de seguros médicos).

b) Escuelas públicas o privadas con reconocimiento oficial de nivel básico, medio, técnico, medio superior, superior e INEA.

c) Expedidas por las autoridades con reconocimiento oficial, excepto la tarjeta postal.

d) Credenciales expedidas por el Instituto Nacional de las Personas Adultas Mayores (INAPAM).

Documentos expedidos por escuelas públicas o privadas de nivel básico, medio, técnico, medio superior, superior e INEA, con reconocimiento oficial, tales como:

a) Título profesional; b) Constancias de estudios; c) Certificado de estudios;

d) Diploma de estudios; e) Carta de Pasante.

Otros documentos.

a) Carta o certificado de naturalización; b) Certificado de Nacionalidad Mexicana;

c) Declaratoria de Nacionalidad Mexicana por naturalización; d) Declaratoria de Nacionalidad Mexicana por nacimiento; e) Matrícula consular e identificación holográfica.

En el caso de que no cuentes con alguno de los documentos de identificación con fotografía señalados:

a) Podrás presentar dos testigos, uno de los cuales deberá estar inscrito en el Padrón Electoral en el mismo Municipio o Delegación y otro de la misma Entidad Federativa.

b) Los testigos deberán identificarse con alguna de sus huellas dactilares o con su Credencial para Votar, manifestar la razón de su dicho bajo protesta de decir verdad, misma que deberá ser asentada en el Acta Testimonial.

c) Sólo podrán serlo hasta por cuatro ocasiones en un lapso de 120 días naturales.

Excepciones a la vigencia:

Sin vigencia:

a) Cartilla del Servicio Militar Nacional; b) Cédula Profesional; c) Credenciales expedidas por el Instituto Nacional de las Personas Adultas Mayores (INAPAM)

\section{Un comprobante de domicilio}

Deberán ser originales y con fecha de expedición no mayor a 3 meses.

Recibos de pago de impuestos y/o servicios públicos:

a) Impuesto predial; b) Luz. (Puede ser descargado de internet); c) Agua.

Recibos de pago de servicios privados:

a) Teléfono. (Puede ser descargado de internet); b) Señal de televisión; c) Gas.

Estados de cuenta de servicios privados

a) Bancarios. (Puede ser descargado de internet); b) De tiendas departamentales. (Puede ser descargado de internet).

Copia certificada de escrituras de propiedad inmobiliaria

Contrato de arrendamiento

a) Deberás presentar el recibo de pago correspondiente.

Excepciones a la vigencia de 3 meses: 
Podrán tener vigencia de 1 año:

a) Pago del impuesto predial; b) Contrato de arrendamiento; c) Recibo de pago de agua cuando el pago sea anual.

Sin vigencia

a) Copia certificada de escrituras de propiedad inmobiliaria.

Se aceptarán comprobantes impresos vía Internet, de aquellas instituciones en las que se compruebe que cuentan con al menos el uso de un usuario y contraseña como mecanismos de seguridad para tener acceso a dichos documentos en formato electrónico.

Uso de Testigos

En caso de que no cuentes con alguno de los comprobantes de domicilio señalados anteriormente, podrás presentar dos testigos:

a) Presentar dos testigos, uno de los cuales deberá estar inscrito en el Padrón Electoral en

el mismo Municipio o Delegación y otro de la misma Entidad Federativa.

b) Los testigos deberán identificarse con alguna de sus huellas dactilares o su Credencial para Votar vigente, manifestar la razón de su dicho bajo protesta de decir verdad, misma que deberá ser asentada en el Acta Testimonial.

c) Sólo podrá ser testigo por cuatro ocasiones en un lapso de 120 días naturales.

d) En caso de utilizar traductor de lengua indígena, se deberá asentar el nombre del traductor en el Acta Testimonial.

La credencial de elector cumple un papel fundamental en lo tocante a los derechos de los ciudadanos contemplados en el artículo 35 CPEUM fracciones I y II, cuando aclara: [...] "I. Votar en las elecciones populares; II. Poder ser votado para todos los cargos de elección popular, teniendo las calidades que establezca la ley. El derecho de solicitar el registro de candidatos ante la autoridad electoral corresponde a los partidos políticos así como a los ciudadanos que soliciten su registro de manera independiente y cumplan con los requisitos, condiciones y términos que determine la legislación".

Por otra parte, se entiende como nación un conglomerado de personas que conviven en un territorio determinado, en donde se comparte una lengua común, clima, las costumbres y la cultura. Tal es el caso de México, que es una república federal, representativa y democrática (art. 40 CPEUM). En este sentido, también habría que tomarse en cuenta lo dispuesto en los artículos 42-48 CPEUM, para ver cuáles son las partes integrantes de la nación mexicana.

Según el artículo 43 CPEUM, México como país cuenta con 32 estados federativos. No obstante, la sede de los tres poderes de la unión será la ciudad de México (art. 44 CPEUM).

Una vez visto cómo se encuentra configurado el concepto de nacionalidad en el ordenamiento jurídico mexicano, pasaremos a ver el concepto de ciudadanía, ya que ambos se encuentran ligados íntimamente; siendo la nacionalidad la columna vertebral para adquirir derechos y obligaciones dentro de una nación.

De acuerdo con el diccionario de la real academia española, la ciudadanía es la "Condición que reconoce a una persona una serie de derechos políticos y sociales que le permiten intervenir en la política de un país determinado". Por su parte la doctrina pone de manifiesto la complejidad que existe para definir ciudadanía, dos pueden ser las formas de referirse a la ciudadanía, una como el simple derecho a tener derechos, que son de ciudadanía cosmopolita, y dos "como el status que se otorga a un conjunto de individuos que son nacionales en un Estado, es decir, quienes tienen una relación social y jurídica con la organización política a la que pertenecen" (Van der Laat, 1998); ciudadanía cualidad que corresponde también a ciudadano, es la cualidad jurídica que tiene toda persona física hombre y mujer - estatal o nacional de una comunidad soberana, que le permite participar en 
los asuntos políticos de un Estado (Venegas, 2004). La CPEUM no define que se entiende por ciudadanía. Sin embargo, en su artículo 34 aclara lo siguiente:

"Son ciudadanos de la República los varones y mujeres que, teniendo la calidad de mexicanos, reúnan, además, los siguientes requisitos:

I. - haber cumplido 18 años, y

II. Tener un modo honesto de vivir.

De la lectura del artículo que venimos comentando, se deduce que no todos los mexicanos son ciudadanos. Siendo requisito esencial tener 18 años de edad y tener un modo honesto de vivir. Aunque, el legislador no aclara que se entiende por modo honesto de vivir. En nuestra opinión, el modo honesto de vivir, se refiere a no atentar contra las buenas costumbres y el decoro de una sociedad. En interpretación de la jurisprudencia electoral, sí se ha definido la locución de modo honesto de vivir involucra "la conducta honesta, contantes asumida y reiterada de una persona en la comunidad donde vive, un comportamiento adecuado para hacer posible la vida civil del pueblo, en resumen un buen mexicano, y es un presupuesto para gozar de las prerrogativas inherente a un ciudadano" (Tesis, 18/2001).

Lo dicho en el párrafo anterior, es de suma importancia, debido a que, en México el sistema electoral exige la ciudadanía como requisito esencial para ocupar cualquier puesto de elección popular, y en particular, los cargos de presidente de la república, diputado y senador, tal y como veremos en las siguientes líneas.

Asimismo, de acuerdo con el sistema electoral, solo pueden votas las personas que cumplan con los siguientes requisitos:

1. Todos los mexicanos mayores de 18 años y que tengan un modo honesto de vivir pueden participar en las elecciones. Sin embargo, para que disfruten de ese derecho es necesario, además, que estén inscritos en el Registro Federal de Electores y cuenten con una credencial para votar con fotografía.

2. Los ciudadanos que hayan sido rehabilitados en sus derechos político-electorales.

3. Los ciudadanos que cuenten con una resolución del Tribunal Electoral del Poder Judicial de la Federación, que en sus resolutivos ordene que se les permita votar.

Por otra parte, los mexicanos al cumplir la mayoría de edad o en la primera oportunidad, si es que no lo han hecho antes, los mexicanos pueden acudir al Módulo de Atención Ciudadana del INE más cercano para solicitar su inscripción en el Registro Federal de Electores. En ese momento sólo es necesario llenar y firmar una solicitud de inscripción, así como tomarse la fotografía que se incluye en la Credencial para Votar.

Al INE le toma alrededor de 20 días realizar todos los trámites de inclusión en el Registro y elaborar la credencial. Cumplido ese lapso, el INE le informa al ciudadano que puede pasar al módulo correspondiente a recogerla. Es indispensable que en ese momento el interesado compruebe su identidad, normalmente mediante la presentación de un documento oficial.

\section{LA CIUDADANÍA COMO ELEMENTO FORMAL PARA SER PRESIDENTE DE LOS ESTADOS UNIDOS MEXICANOS}

Antes de responder al título del presente epígrafe, debemos señalar que de acuerdo con el artículo 80 de la CPEUM se deposita el ejercicio del supremo poder ejecutivo de la unión en un solo individuo, que se denominara "presidente de los Estados Unidos Mexicanos". En el mismo sentido se pronuncia el artículo nueve del Código Federal de Procedimientos 
Electorales (COFIPE) al declarar: "El ejercicio del Poder Ejecutivo se deposita en un solo individuo que se denomina Presidente de los Estados Unidos Mexicanos electo cada seis años por mayoría relativa y voto directo de los ciudadanos mexicanos" (Cámara, 2014).

Cabe aclara que el presidente entrará a ejercer su encargo el primero de octubre y durará en él seis años (art. 83 CPEUM). Antes de la reforma política-electoral, el presidente de la republica tomaba posesión de cargo el día primero de diciembre del año en que se hubiera llevado a cabo la elección.

El primer presidente que duro en su encargo seis años en el México moderno, después de promulgarse la constitución de 1917, fue Lázaro Cárdenas del Rio, quien gobernó en el periodo de 1934-1940. Desde entonces todos los presidentes de México que hasta la fecha han gobernado han durado en su encargo seis años.

Dentro de los requisitos de que la CPEUM exige para ser presidente de la república se encuentran los siguientes (art 82):

Para ser Presidente se requiere:

I. Ser ciudadano mexicano por nacimiento, en pleno goce de sus derechos, hijo de padre o madre mexicanos y haber residido en el país al menos durante veinte años.

II. Tener 35 años cumplidos al tiempo de la elección;

III. Haber residido en el país durante todo el año anterior al día de la elección. La ausencia del país hasta por treinta días, no interrumpe la residencia.

[...]

VII. No estar comprendido en alguna de las causas de incapacidad establecidas en el artículo 83.

Como podemos ver, el primer requisito que se exige para ser presidente de la república es la ser ciudadano por nacimiento, hijo de padre o madre mexicanos. Cabe señalar, que hasta antes de 1994 se exigía como requisito esencial para poder ser candidato a la presidencia de la republica ser ciudadano mexicano de padre y madre mexicanos. Sin embargo, hoy en día esto ha cambiado, por lo tanto, pueden ser candidato a presidente de la republica el ciudadano mexicano, ya sea hijo de padre o madre mexicana. Sin duda uno de los grandes beneficiados con esta reforma fue el expresidente mexicano Vicente Fox Quesada, quien es hijo de una española naturalizada mexicana (Mercedes Quezada Etxaide).

A diferencia que para ser diputado federal la CPEUM exige 21 años cumplidos el día de la elección, y para ser senador se exigen 25 años cumplidos el día de la elección. El artículo 82II CPEUM, exige tener 35 años cumplidos al tiempo de la elección. Además de haber residido en el país durante 20 años, y, haber residido en el país durante todo el año anterior al día de la elección. Siendo requisito esencial tener, tanto la nacionalidad mexicana como la ciudadanía.

\section{LA CIUDADANÍA COMO ELEMENTO FORMAL PARA SER DIPUTADO Y SENADOR}

En acápite anterior se ha dejado clarificado que se debe entender por ciudadanía, lo que permite inferir, que el ciudadano en sentido amplio son todos los individuos de una nación; sin embargo, para efectos del tema de derechos políticos hay que atenerse a lo que dispone la Ley Fundamental.

Según el artículo 55 de la CPUEM Para ser diputado se requiere los siguientes requisitos:

I. Ser ciudadano mexicano, por nacimiento, en el ejercicio de sus derechos. 
II. Tener veintiún años cumplidos el día de la elección;

III. Ser originario de la entidad federativa en que se haga la elección o vecino de esta con residencia efectiva de más de seis meses anteriores a la fecha de ella.

Para poder figurar en las listas de las circunscripciones electorales plurinominales como candidato a diputado, se requiere ser originario de alguna de las entidades federativas que comprenda la circunscripción en la que se realice la elección, o vecino de ella con residencia efectiva de más de seis meses anteriores a la fecha en que la misma se celebre.

La vecindad no se pierde por ausencia en el desempeño de cargos públicos de elección popular.

$[\ldots]$

VII. No estar comprendido en alguna de las incapacidades que señala el artículo 59.

Para ser senador se requieren los mismos requisitos que para ser diputado excepto la edad que será de 25 años al día de la elección (art. 58 CPEUM).

Por lo que ahora nos interesa nos centraremos en la fracción primera del artículo 55, el cual tiene una relación directa con nuestro objeto de estudio. Al igual que para ser presidente de la república para ser diputado o senador se exige ser ciudadano por nacimiento. Lo anterior cobra importancia, debido a que el artículo 32 segundo párrafo de la CPUEM señala: "El ejercicio de los cargos y funciones para los cuales, por disposición de la presente Constitución, se requiera ser mexicano por nacimiento, se reserva a quienes tengan esa calidad y no adquieran otra nacionalidad. Esta reserva también será aplicable a los casos que así lo señalen otras leyes del Congreso de la Unión”. Asimismo, el último párrafo del artículo en comento aclara:

"Los mexicanos serán preferidos a los extranjeros en igualdad de circunstancias, para toda clase de concesiones y para todos los empleos, cargos o comisiones de gobierno en que no sea indispensable la calidad de ciudadano".

De esta manera, la nacionalidad y la ciudadanía se convierten en elementos formales para los cargos de elección popular en el ordenamiento jurídico mexicano.

\section{CONCLUSIONES}

Como pudimos ver a lo largo del presente trabajo, que en México la nacionalidad y la ciudadanía, se convierten en requisitos formales para ocupar cualquier puesto de elección popular en términos de su ordenamiento jurídico.

Que el primer requisito que exige la Constitución Federal para ser presidente de la república, diputado o senador es ser ciudadano mexicano por nacimiento. Asimismo, la Suprema Corte de Justicia de la Nación ha dejado claro que la nacionalidad mexicana por naturalización se acredita mediante la credencial de elector, la cual como vimos se puede obtener de distintas maneras, esto de acuerdo con la normativa electoral.

Por otro lado, la Constitución no aclara que debe entenderse por nacionalidad y ciudadanía, por lo tanto, tuvimos que recurrir a la doctrina para aclarar este punto. Además, la constitución solo señala como se adquiere la nacionalidad y en qué casos se pierde. De la interpretación armónica entre lo previsto en la Constitución, las Leyes Reglamentarias de Nacionalidad, Ley General de Población, la Jurisprudencia y la doctrina, se puede sostener, que en el desarrollo del Estado democrático, la ciudadanía como derecho fundamental de la persona en sistema político converge con el de nacionalidad, porque un ciudadano es la 
persona que presenta valores éticos, conducta de integración, respecto, impregnada de aprecio en la comunidad o nación de la que es miembro, "un modo honesto de vivir", porque un presidente de la república, diputado o senador, deben ser personas que tengan del aprecio y la confianza de los miembros de la "nación".

\section{BIBLIOGRAFÍA}

Cámara de Diputados del H. Congreso de la Unión (2012) Ley de Nacionalidad 2012, accesible en https://goo.gl/4AoAxl

Cámara de Diputados del H. Congreso de la Unión (2014) Código Federal de Instituciones y Procedimientos Electorales 2014, accesible en https://goo.gl/hE23kJ

Cámara de Diputados del H. Congreso de la Unión (2015) Ley General de Población 2015, accesible en https://goo.gl/qu1rS9

Cámara de Diputados del H. Congreso de la Unión (2017) Constitución política de los Estados Unidos Mexicanos 2017, accesible en https://goo.gl/vCcxDN

Carpizo McGregor J. (2004) Enciclopedia Jurídica mexicana. México: Porrúa, pp. 180-194.

Gaceta de Jurisprudencia y Tesis en materia electoral, Tribunal Electoral del Poder Judicial de la Federación, Año 4, Número 8, 2011, pp. 16, 17 y 18.

García Bartolo, M. S. (2011) "Las reformas electorales a nivel federal en México", El cotidiano 166: 79-91.

Instituto Nacional Electoral (2017) Credencial para votar, accesible en https://goo.gl/2vPRGe

Lapiedra Alcamí, R. et al, (2011) Manuales de Derecho Administrativo, Financiero e Internacional Público. Valencia: Tirant lo Blanch, p. 20.

Martínez Gil, J. P. y Ruvalcaba García, G. D. (2010) "Ley general del sistema de medios de impugnación en materia electoral (LGSMIME)". En L.A. Corona Nakamura y A. Miranda Camarena (Comps.) Derecho electoral, mexicano. Una visión local: Jalisco, Madrid: Marcial, pp. 151-173.

Tesis 18/2001 (2002) "Justicia Electoral". Revista del Tribunal Electoral del Poder Judicial de la Federación, Suplemento 5, pp. 22 y 23, accesible en https://goo.gl/CjJBxp

Van der Laat, P. L. (1998) "El concepto de ciudadanía y su contenido". En H. Fix-Zamudio, Liber Amicorum. San José Costa Rica: Corte Interamericana de Derechos Humanos, pp. 947-985. Volumen II.

Venegas Trejo, F. (2004) “Ciudadanía”. Enciclopedia jurídica mexicana, T.II. C. México: PorrúaUNAM.

\section{Breve currículo:}

\section{Egla Cornelio Landero}

Doctora en Métodos de Solución de Conflictos y Derechos Humanos, en la Universidad Juárez Autónoma de Tabasco, México. Maestría de Derecho Constitucional, Amparo y Derechos, Humanos; Maestría en Resolución de Conflictos y Mediación, por la Universidad Juárez Autónoma de Tabasco, México; y Máster en Gestión y Resolución de Conflictos por la Universidad de Barcelona. Miembro del Padrón Estatal de Investigadores en el Estado de Tabasco; Académica de Número de la Academia de Derecho del Trabajo y de la Previsión Social en México. Líneas de investigación Mecanismos de Solución de Conflictos y Derechos Humanos; Conflictos laborales y Seguridad Social. Profesora Investigadora de la Universidad Juárez Autónoma de Tabasco, México. 